\title{
Penguatan Kapasitas Pokdarwis untuk Pengurangan Risiko Bencana di Destinasi Pariwisata Dieng
}

\author{
Desta Titi Raharjana1, Mohamad Yusuf ${ }^{2}$, Arry Retnowati ${ }^{3}$ \\ ${ }^{1}$ Pusat Studi Pariwisata Universitas Gadjah Mada, ${ }^{2}$ Fakultas Ilmu Budaya \\ Universitas Gadjah Mada, ${ }^{3}$ Fakultas Geografi Universitas Gadjah Mada \\ Korespondensi: myusuf@ugm.ac.id
}

\begin{abstract}
Efforts to reduce disaster risks should be a main endeavour in every development, including in tourism sector. In many places, the tourism industry is vulnerable to disasters, either directly or indirectly. Either the tourism sector triggers disasters, or it can be affected by disasters. The Dieng Plateau area is one of the leading tourism destinations in Central Java which has potentials to attract tourists. But behind its beautiful charm, this destination holds a threat. The people of Dieng Kulon, Batur District, Banjarnegara Regency, Central Java live in a disaster-prone area. They do not forget the series of disasters had occured around them. On the other hand, the surrounding nature in the village provides economic benefits, one of them comes from the tourism sector. The disaster risk reduction (DRR) approach is strategic to be applied in this village. Through the Education for Sustainability Development (ESD) program, the Dieng Pandawa Tourism Awareness Group (Pokdarwis) has to be strengthened its role so that the Pokdarwis is able to become one of the elements in DRR, especially the ability related to the process of rescueing tourists. Disaster threats on a tourism location makes the tourism industry very vulnerable, but it should be attempted that this destination or industry will become resilient at the same time. Disaster risk reduction programs and capacity building for Pokdarwis are strategic to be implemented and directed in building disaster mitigation plans.
\end{abstract}

Keywords: disaster risk reduction; tourism; Pokdarwis; Dieng Kulon Village

\begin{abstract}
Abstrak
Upaya mengurangi resiko bencana perlu menjadi arus utama dalam setiap pembangunan, termasuk di sektor kepariwisataan. Di banyak tempat, industri pariwisata rentan dengan bencana, baik secara langsung ataupun tidak langsung. Di satu pihak sektor pariwisata memicu terjadinya bencana, tetapi di pihak lain dapat menjadi yang terdampak. Kawasan Dieng Plateau salah satu destinasi pariwisata unggulan Jawa Tengah yang potensial mendatangkan wisatawan. Namun di balik pesonanya yang indah, destinasi ini menyimpan ancaman. Masyarakat Dieng Kulon, Kecamatan Batur, Kabupaten Banjarnegara Jawa Tengah tinggal di kawasan rentan bencana. Mereka tidak lupa terhadap rentetan kejadian bencana di sekitar mereka tinggal. Di sisi lain, alam sekitar di desa memberikan manfaat ekonomi, salah satunya dari sektor pariwisata. Pendekatan pengurangan resiko bencana (PRB) menjadi strategis untuk diterapkan di desa tersebut. Melalui program Education for Sustainabe Deveopment (ESD), Kelompok Sadar Wisata (Pokdarwis) Dieng Pandawa diperkuat perannya supaya mampu menjadi salah satu unsur dalam PRB, khususnya kemampuan terkait proses penyelamatan wisatawan. Adanya ancaman bencana terhadap lokasi pariwisata menjadikan industri pariwisata sangat rapuh (vulnerable), tetapi di pihak lain diharapkan secara bersamaan destinasi atau industri ini menjadi tangguh
\end{abstract}


(resilient). Program pengurangan resiko bencana dan penguatan kapasitas Pokdarwis menjadi strategis untuk dijalankan dan diarahkan untuk menyusun perencanaan mitigasi bencana.

Kata kunci: pengurangan resiko bencana; pariwisata; Pokdarwis; Desa Dieng Kulon

\section{Pendahuluan}

Konsep keberlanjutan (sustainability) penting untuk dijadikan landasan pada berbagai sektor, termasuk dalam bidang kepariwisataan. Sebagai sebuah aktivitas sosial, ekonomi dan budaya, pariwisata merupakan sektor yang dipercaya mampu memberikan kontribusi yang nyata bagi pengembangan ekonomi sekaligus mendorong hadirnya nilai-nilai baru seiring dengan berkembangnya arus globalisasi. Di pihak lain, seperti ditegaskan oleh Faulkner (2001), di beberapa belahan dunia terjadi pertambahan jumlah kejadian bencana dan krisis yang semuanya turut mempengaruhi industri pariwisata, baik bencana alam maupun bencana yang diakibatkan kesalahan manusia. Industri pariwisata pun tidak pelak mengalami terpaan akibat bencana ${ }^{1}$. Salah satunya adalah kawasan Dieng Plateau, Banjarnegara Jawa Tengah yang menjadi lokasi program Education for Sustainable Development (ESD) ini.

Rentetan catatan sejarah bencana alam akibat gunung berapi dan tanah longsor di areal Dieng masih dapat dijumpai ${ }^{2}$. Kawasan Pariwisata Dataran Tinggi Dieng termasuk daya tarik wisata pegunungan. Berada pada ketinggian 2.000-2.500 mdpl. Sukatno (2004) menjelaskan bahwa Dieng merupakan daerah vulkanis yang masih aktif, hal ini antara lain dapat dilihat dari aktivitas kawah Si Kidang yang selalu menyemburkan asap belerang bewarna putih pekat ${ }^{3}$. Kondisi daerah wisata Dieng yang rentan bencana memang masih dapat dijumpai hingga saat ini. Padahal dulunya pesona ekosistem Dieng Plateau adalah hutan lindung. Rerimbunan pepohonan tampak asri dengan dilengkapi aura mistis adanya beragam situs serta percandian bercirikan Hindu. Dieng dikenal sebagai tempat bersemayamnya para dewa karena lokasinya berada di daerah tinggi (Supeno, 2016; Sukatno, 2004; Mubin, 2016). Penggunaan lahan kemudian berubah ketika pola pertanian warga beralih ke budidaya kentang (Solanum tuberosum L.) sebagai tanaman pokok bagi petani Dieng.

Pada periode tahun 1970an, masyarakat Dieng mengganti tanaman tembakau dengan tanaman kentang, karena secara ekonomi tanaman kentang lebih menjanjikan. Sejak itu masyarakat Dieng mulai lebih berorientasi pada pertumbuhan ekonomi, tanpa memperhitungkan aspek lainnya seperti kerusakan lingkungan (Hermanto, 2014, 2015; Ngabekti, 2007). Pesona mistis dan hijaunya Dieng plateau mulai terusik dengan perubahan ekosistem yang berlangsung. Wilayah konservasi dan areal percandian yang

1 Lihat: https://www.academia.edu/14306749/Mengembangkan_Desa_Wisata_di_Kawasan_ Bencana_Lereng_Merapi Yogyakarta

2 http://www.mediaindonesia.com/news/read/111115/di-balik-pesona-dieng-ada-bahaya-yangmematikan/2017-07-02

3 Bukti lainnya yang memperkuat aktifnya kondisi geologi Kawasan Pariwisata Dataran Tinggi Dieng adalah meletusnya Kawas Sileri, 2 Juli 2017. Kepala BNPB, Sutopo Purwo Nugroho menjelaskan bahwa tipe letusan Kawah Sileri adalah letusan jenis freatik, yaitu letusan gas atau hembusan asap dan material yang dipicu oleh tekanan gas yang berada di bawah permukaan. Akibat kejadian tersebut tidak ada korban jiwa namun kawasan Kawah Sileri disterilkan dari aktivitas warga dan pariwisata untuk sementara waktu (Kedaulatan Rakyat,3 Juli 2017). 
semestinya steril dari aktivitas pertanian pun harus bergesekan dengan usaha budidaya petani monokultur yang secara masif mendesak lahan konservasi dengan pola tanam yang tidak mengikuti kaidah konservasi (Nurlaila, 2014; Hermanto, 2015). Pola tanam yang tidak memperhatikan lingkungan fisik, khususnya topografi dan sumber air, mengakibatkan potensi gerakan tanah di beberapa lokasi di kawasan Dieng.

Kesejukan Dataran Tinggi Dieng mulai berkurang, jika dibandingkan dengan 10 tahun yang lalu (informasi responden, 2018). Rimbunnya pepohonan di perbukitan kini sebagian sudah berubah menjadi lahan yang ditanami kentang. Tidak banyak lagi tegakan yang fungsinya untuk menahan laju air hujan. Kondisi ini diperparah dengan eksploitasi sumberdaya air yang bersumber di mata air dan telaga yang tersebar di kawasan Dieng. Para petani menyirami tanaman kentang dengan air yang diperoleh dengan cara memompa air telaga. Ratusan pipa pralon menjulur, melintang di kiri, kanan dan atas jalan raya sudah menjadi pemandangan umum. Para pelancong yang datang ke Dieng selain terpesona keindahan alamnya, juga takjub melihat kegigihan petani Dieng membudidayakan tanaman kentang. Ekonomi kentang mengubah wajah Dieng secara dratis (Thohir, 2007, Ngabekti, 2007). Di pihak lain, lingkungan yang rusak tentu berdampak pada keberlanjutan pariwisata. Sektor jasa wisata di kawasan Dieng keberlanjutannya tergantung pada kondisi lingkungannya (Antariksa, 2016; Damanik, 2013; Wahab dan Pigram, 1997, Holden, 2008).

Dalam peningkatan kapasitas masyarakat untuk pengurangan resiko bencana (PRB), perlu diberikan penekanan program pendidikan pembangunan berkelanjutan (Education for Sustainable Development). Peningkatan kapasitas masyarakat yang menetap di lokasi wisata yang rentan bencana perlu diperhatikan juga. Masyarakat awam dan pelaku wisata di Kawasan Dieng dapat diberikan pengetahuan dan ketangkasan sebagai proses pembelajaran sepanjang hayat agar mereka secara mandiri mampu mengatasi problem ekonomi, lingkungan, dan sosial di kawasan rentan bencana.

Pertimbangan-pertimbangan tersebut di atas mendorong perlunya penerapan manajemen bencana dalam suatu destinasi pariwisata. Industri pariwisata yang dijalankan bukan saja harus berkelanjutan namun juga menjadi industri menjadi tangguh (resilient). Pada umumnya lokasi yang unik, menarik dan atraktif bagi para wisatawan justru berada di wilayah yang memiliki resiko bencana, seperti gunungapi, dataran tinggi, dan pantai. Pendekatan pengurangan resiko bencana sangat diperlukan mengingat resiko bencana dapat terjadi kapan dan dimana pun, termasuk di lokasi wisata. Dalam kerangka konsep disaster risk management (DRM), resiko dijelaskan sebagai probabilitas dari konsekuensi bahaya atau kemungkinan kehilangan atau kerugian akibat terjadinya bencana krisis. Manajemen resiko bencana adalah suatu proses yang terintegrasi guna meminimalkan kerugian/kehilangan dan memaksimalkan peluang dari kemunculan bencana/krisis yang memberikan pengaruh pada industri pariwisata secara langsung ataupun tidak langsung (Nurdiyansah, 2014).

Dalam memberikan intervensi kepada masyarakat ataupun sekelompok organisasi tertentu mengenai pendidikan untuk pembangunan berkelanjutan, khususnya di bidang pengurangan resiko bencana dan mitigasi patut memperhatikan kondisi sosial budaya dan disesuaikan dengan kondisi lokal (McKeown,2000). Atas dasar inilah, peran perguruan tinggi untuk mendorong terjadinya proses transfer knowledge yang diharapkan mampu memberikan pemahaman sekaligus kesadaran bagi kelompok sasaran guna melakukan 
pengelolaan, perbaikan serta penyelamatan kehidupan manusia dan lingkungan, baik untuk masa kini dan masa mendatang. Pemberian pemahaman (knowledge) yang dilengkapi dengan pelatihan (action) dapat melalui pendidikan non-formal lewat pendekatan partisipatif ${ }^{4}$ guna menghasilkan dampak atas proses pembelajaran secara berkelanjutan.

Urgensi pendidikan pengurangan resiko bencana dan mitigasi menjadi agenda strategis yang harus diberikan kepada kelompok masyarakat, ataupun masyarakat lebih luas yang tinggal dan menetap di daerah rawan bencana, dalam hal ini wilayah Dieng Plateau 5 sebagai lokusnya. Terkait dengan upaya pengembangan destinasi pariwisata, isu terpenting yang patut diperhatikan adalah keberlanjutan destinasi yang secara konseptual diharapkan melahirkan pola-pola pengembangan pariwisata yang mengacu pada prinsip-prinsip pembangunan berkelanjutan ${ }^{6}$. Setidaknya terdapat empat kriteria penting pengembangan destinasi pariwisata berkelanjutan, yaitu: (1) pengelolaan destinasi pariwisata berkelanjutan, (2) pemanfaatan ekonomi untuk masyarakat lokal, (3) pelestarian budaya bagi wisatawan dan masyarakat, serta (4) pelestarian lingkungan. Konsepsi pembangunan pariwisata berkelanjutan tentunya gayut dengan pendidikan untuk pembangunan berkelanjutan (ESD) yang indikator keberhasilannya ditandai dengan munculnya kesadaran, tanggung jawab dan perubahan perilaku sekaligus terjadinya peningkatan kemampuan untuk melakukan mitigasi terhadap kerusakan lingkungan/bencana.

\section{Pendekatan Pelaksanaan Program}

Lokasi kegiatan pengabdian masyarakat melauli ESD ini diberikan kepada Kelompok Sadar Wisata Dieng Pandawa, Desa Dieng Kulon, Kecamatan Batur, Banjarnegara. Dieng berada pada wilayah berbukit dengan jalan yang menanjak, menurun dan berkelok. Sebagai kawasan wisata, tentunya diperlukan aksesbilitas yang baik. Wisatawan yang hendak ke Dieng umumnya melalui Kabupaten Wonosobo. Dieng Kulon dipilih sebagai lokasi ESD ini dengan pertimbangan bahwa Pokdarwis Dieng Pandawa memiliki peran sentral sebagai lembaga yang bergerak di kawasan pariwisata Dieng. Mereka perlu diberikan memiliki bekal terkait mitigasi bencana. Selain itu, Dieng Kulon sebagai pusat wisata kawasan Dieng, sudah banyak tersedia fasilitas wisata yang perlu dilengkapi dengan infrastruktur tanggap bencana serta ditunjang kualitas SDM yang tanggap bencana.

\section{Cara Pengumpulan Data}

a. Desk study

Langkah ini ditempuh untuk mendapatkan pengkayaan atas fenomena kebencanaan

4 Dalam konsep dan implementasinya, penerapan ESD sangat diharapkan mampu menjalin sinergi dalam dan bersama masyarakat (community based), sebagai wahana pendidikan transformatif dan bersifat berkesinambungan. Lihat: Panduan Hibah ESD masyarakat, 2018.

5 Kawasan Pariwisata Dieng Plateau mencakup Kabupaten Banjarnegara dan Kabupaten Wonosobo, Jawa Tengah. Secara mikro hibah pengabdian ESD ini difokuskan pada Kelompok Sadar Wisata (Pokdarwis) desa Dieng Kulon, Kec. Batur, Kab.Banjarnegara.

6 Lihat: Peraturan Menteri No 14 Tahun 2016 tentang Pedoman Destinasi Pariwisata Berkelanjutan. 
di daerah wisata, khususnya yang terjadi di kawasan Dieng. Beberapa kliping media ataupun referensi dari hasil penelitian sebelumnya serta berbagai jurnal seputar isu kebencanaan di destinasi Dieng Plateau coba ditelaah. Hasilnya, dari proses dan tahapan desk study tim mampu mendapatkan gambaran atas situasi dan kondisi riil di dataran tinggi Dieng, khususnya persoalan bencana yang selama ini pernah terjadi dan mendera masyarakat di kawasan Dieng.

\section{b. Observasi/Pengamatan Lapangan}

Destinasi Dieng Plateau menyimpan pesona alam dan budaya. Namun tidak sedikit lokasi wisata rentan terhadap bencana. Dari hasil pengamatan di Desa Dieng Kulon, di kawasan Dieng Plateau terdapat potensi wisata kawah. Kawah yang ada yaitu Kawah Sikidang yang selalu ramai dikunjungi wisatawan, kawah Sileri yang sudah jarang dikunjungi wisatawan, dan beberapa kawah lainnya yang sudah tidak dipergunakan untuk pariwisata. Selain itu, ada museum yang menyimpan koleksi etnografi masyarakat Dieng. Beberapa signage atau tanda jalur evakuasi sudah terpasang pada beberapa lokasi, seperti di tepi jalan dekat beberapa objek wisata, kantor desa sebagai barak, madrasah, lapangan/tanah lapang, dan di beberapa lokasi wisata telah terpasang tanda "bahaya" jenis tertertu (lihat gambar 1).

Kegiatan observasi dilakukan di Pos Pengamatan Gunungapi Dieng, yang berlokasi di Desa Karangtengah. Kantor ini di bawah kewenangan Kementerian Energi dan Sumberdaya Mineral Badan Geologi. Pos ini berfungsi sebagai pusat informasi vulkanologi dan mitigasi bencana geologi (lihat gambar 2).

\section{c. Focused Group Discussion (FGD)}

Pelaksanaan diskusi terfokus ini dijalankan sebagai proses pengumpulan data. Kegiatan FGD dilakukan bersama pengurus Pokdarwis dan perangkat desa Dieng Kulon serta tokoh masyarakat (lihat Gambar 3). Pada FGD ini diperoleh informasi pengetahuan masyarakat lokal terkait kebencanaan, khususnya sejarah kejadian bencana dan upaya yang dilakukan. Pada kesempatan sharing bersama ini menghasilkan beberapa kesepakatan terkait dengan lokasi yang biasa dan mungkin sebagai alternatif lokasi evakuasi pada saat krisis.
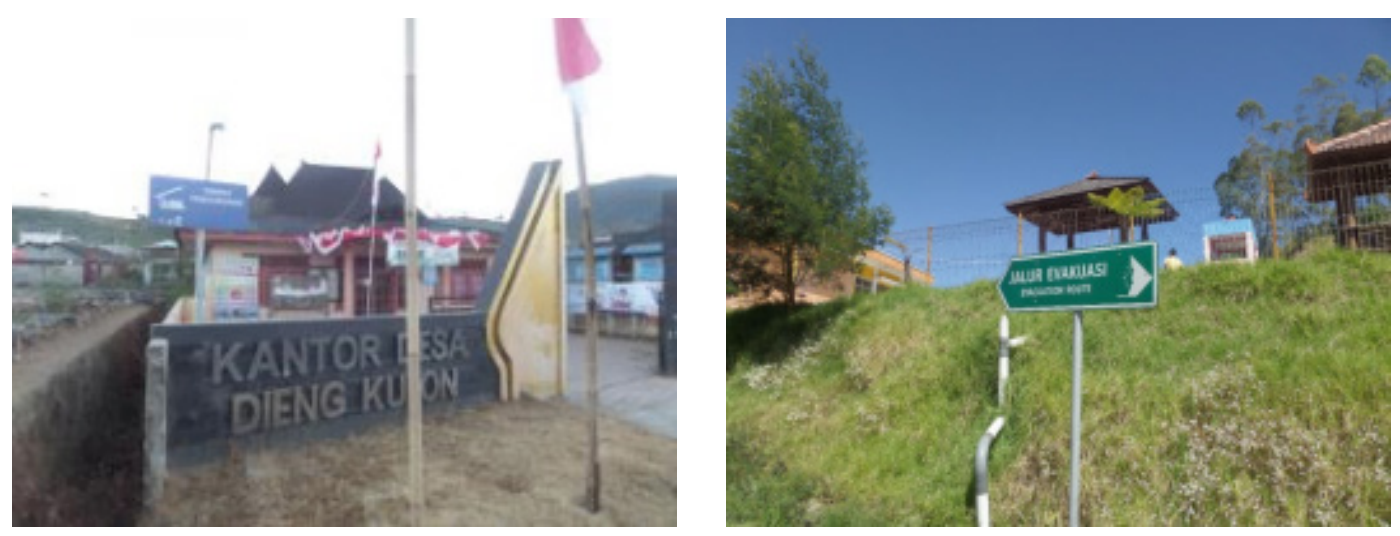

Gambar 1. Kantor balai desa Dieng Kulon (kiri) sebagai salah satu lokasi barak penampungan jika terjadi bencana di Dieng. Rambu jalur evakuasi (kanan) yang saat ini terpasang di salah satu titik berdekatan dengan objek wisata. (Foto/Teks: tim ESD-Puspar UGM, 2018) 

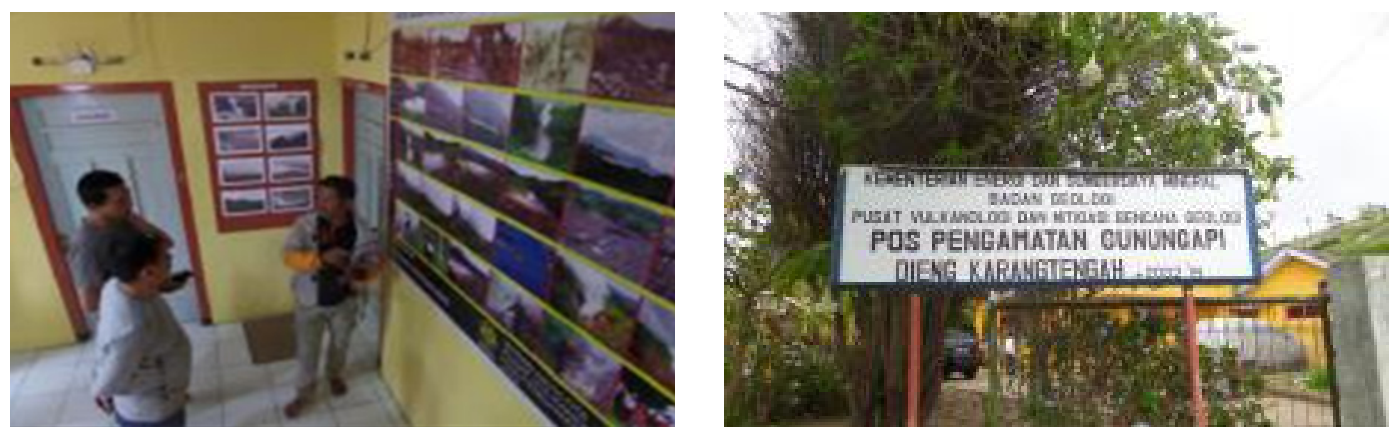

Gambar 2. Kegiatan di ruang PVMBG Dieng.

(Foto/Teks: tim ESD-Puspar UGM- 2018.
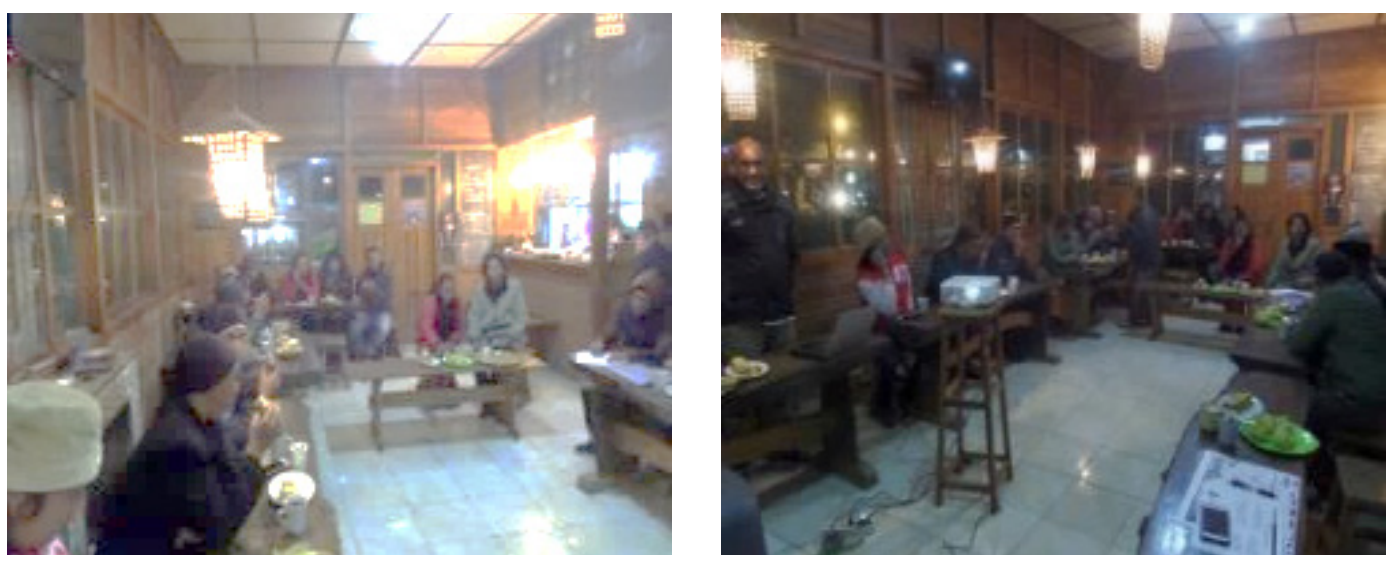

Gambar 3. Suasana diskusi terfokus bersama Kelompok Sadar Wisata Dieng Pandawa, Bapak Kepala Desa Dieng Kulon, Kepala BPD, Bapak RT, dan beberapa tokoh masyarakat Dieng Kulon. (Foto/Teks: tim ESD-Puspar UGM- 2018).
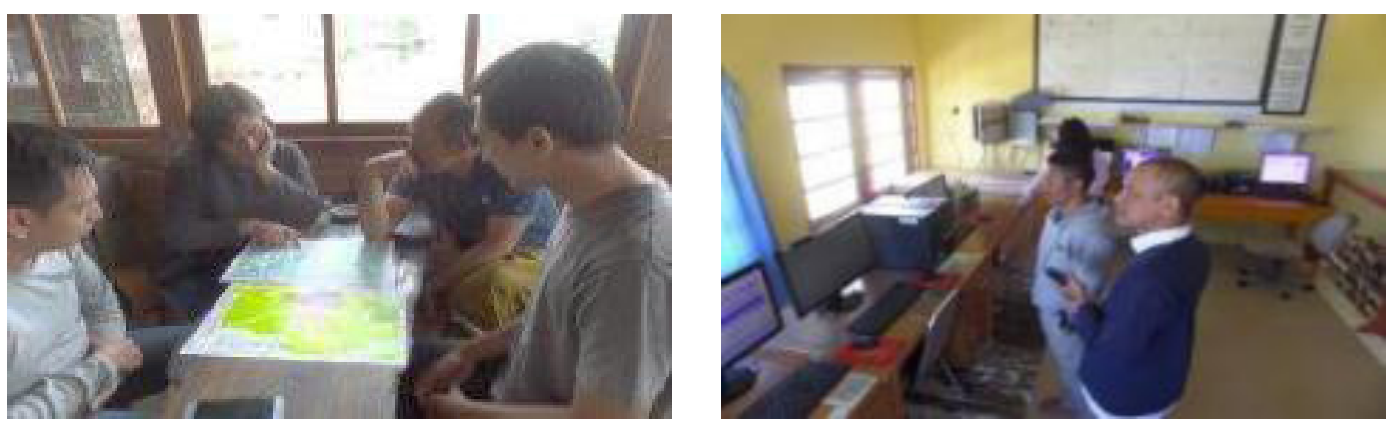

Gambar 4. Wawancara mendalam dan diskusi peta bersama Kepala Desa Dieng Kulon dan Ketua Pokdarwis (kiri), kegiatan wawancara di ruang kantor PVMBG Dieng (kanan). Foto/Teks : tim ESD-Puspar UGM- 2018.

d. Wawancara Mendalam

Wawancara mendalam dilakukan bersama dengan tokoh atau informan kunci di Dieng Kulon, yaitu Kepala Desa, Ketua Pokdarwis, dan petugas pos pengamatan PVMBG (lihat Gambar 4). Informan kunci di kantor PVMBG Dieng adalah Bapak Surip. Beliau adalah petugas yang secara komprehensif memberikan penjelasan terkait tupoksi dan seputar kondisi geologi dan berbagai ancaman geologi yang sering muncul di wilayah Dieng. 


\section{Pelaksanaan Program}

Bagian ini menjelaskan hasil kajian pustaka, telaah dokumen/data sekunder, hingga kegiatan obeservasi lapangan dan pelaksanaan FGD bersama pengelola dan perangkat desa Dieng Kulon. Sebelumnya akan dijelaskan gambaran singkat kawasan Dieng Plateau, sumber daya pariwisata Dieng Plateau, gambaran kawasan desa Dieng Kulon, sarana akomodasi wisata yang disiapkan masyarakat, dan penjelasan terkait tentang Kelompok Sadar Wisata (Pokdarwis) Dieng Pandawa.

\section{Potensi Daya Tarik Pariwisata Kawasan Dieng}

Sebaran daya tarik wisata yang terdapat di destinasi pariwisata Dieng terbagi dalam konsep "poros” dan “jeruji”. Kawasan Poros merupakan kawasan yang memiliki objek yang menjadi ikon atau penggerak aktivitas pariwisata. Sementara, kawasan Jeruji merupakan kawasan yang memiliki objek wisata yang pendukung objek di kawasan Poros. Kawasan Poros tersebut adalah Kompleks Candi Arjuna, Kawah Sikidang, Dieng Plateau Theatre, Telaga Warna dan Telaga Pengilon. Keempat objek wisata tersebut berada di desa Dieng Kulon, Kecamatan Batur, Kabupaten Banjarnegara dan desa Dieng Wetan, Kecamatan Kejajar, Kabupaten Wonosobo. Selain itu masih terdapat objek-objek wisata yang lain, tujuh di antaranya masuk kedalam wilayah desa Dieng Kulon dan sepuluh objek lainnya berada di desa Dieng Wetan. Daya tarik wisata yang terdapat dalam kawasan Poros ini memiliki karakteristik yang sangat beragam, mulai dari wisata alam, wisata budaya bahkan sampai kepada wisata buatan. Selanjutnya, kawasan Jeruji Dieng teridentifikasi sebagai destinasi wisata di sekitar kawasan poros yang fungsinya menjadi supporting atractions. Sebaran objek wisata milik kab. Banjarnegara yang masuk kawasan Poros wisata Dieng dapat dilihat pada tabel berikut.

Tabel 1. Sebaran Daya Tarik Wisata Kawasan “Jeruji” Wisata Dieng (Masuk di Wilayah Kabupaten Banjarnegara)

\begin{tabular}{|c|c|c|c|c|}
\hline \multirow{2}{*}{ No } & \multirow{2}{*}{ Daya Tarik Wisata } & \multicolumn{2}{|c|}{ Lokasi } & \multirow{2}{*}{$\begin{array}{c}\text { Jarak dari pusat } \\
\text { Kawasan Poros }\end{array}$} \\
\cline { 3 - 4 } & Telaga Merdada & Karang Tengah & Batur & $5 \mathrm{Km}$ \\
\hline 2 & Kawah Sileri & Kepakisan & Batur & $6 \mathrm{Km}$ \\
\hline 3 & $\begin{array}{c}\text { Pemandian Air } \\
\text { Panas Bitingan }\end{array}$ & Kepakisan & Batur & $9 \mathrm{Km}$ \\
\hline 4 & Curug Sirawe & Kepakisan & Batur & $9 \mathrm{Km}$ \\
\hline 5 & Sumur Jalatunda & Pekasiran & Batur & $8 \mathrm{Km}$ \\
\hline 6 & Gua Jimat & Pekasiran & Batur & $7 \mathrm{Km}$ \\
\hline 7 & Kawah Candradimuka & Pekasiran & Batur & $10 \mathrm{Km}$ \\
\hline 8 & Telaga Dringo & Pekasiran & Batur & $11 \mathrm{~km}$ \\
\hline
\end{tabular}

Sumber: Dinas Pariwisata Kabupaten Banjarnegara Catatan: Jarak dari Kawasan Poros merupakan perkiraan dalam radius jarak dengan satuan Km terhitung dari lokasi Kelompok Candi Arjuna sebagai titik episentrum dari kawasan wisata Dieng. 
Sementara delapan objek wisata yang masuk Jeruji atau pendukung pariwisata Kawasan Poros Wisata Dieng yang terdapat di Kabupaten Wonosobo ada dalam tabel di bawah ini.

Tabel 2. Sebaran Daya Tarik Wisata Kawasan Jeruji Wisata Dieng (Masuk di Wilayah Kabupaten Wonosobo)

\begin{tabular}{|c|c|c|c|c|}
\hline \multirow{2}{*}{ No } & \multirow{2}{*}{ Daya Tarik Wisata } & \multicolumn{2}{|c|}{ Lokasi } & \multirow{2}{*}{$\begin{array}{c}\text { Jarak dari pusat } \\
\text { Kawasan Poros }\end{array}$} \\
\cline { 3 - 4 } & & Desa & Kecamatan & Kajajar \\
\hline 1 & Ondho Bodho & Sikunang & Kejaj & $6 \mathrm{~km}$ \\
\hline 2 & Telaga Cebong & Sembungan & Kejajar & $6 \mathrm{~km}$ \\
\hline 3 & Gardu Pandang & Tieng & Kejajar & $6 \mathrm{~km}$ \\
\hline 5 & Gunung Sikunir & Sembungan & Kejajar & $9 \mathrm{~km}$ \\
\hline 6 & Air terjun Sikarim & Sembungan & Kejajar & $9 \mathrm{~km}$ \\
\hline 7 & Air terjun Seloka & Sembungan & Kejajar & $10 \mathrm{~km}$ \\
\hline 8 & Agrowisata Tambi & Tambi & Kejajar & $18 \mathrm{~km}$ \\
\hline
\end{tabular}

Sumber: Dinas Pariwisata Kabupaten Wonosobo

Catatan: Jarak dari Kawasan "Poros" merupakan perkiraan dalam radius jarak dengan satuan Km terhitung dari lokasi Kelompok Candi Arjuna sebagai titik episentrum dari kawasan wisata Dieng.

Selain daya tarik alam yang tersebar pada dua kabupaten, daya tarik budaya lokal yang masih dapat dijumpai di Dieng adalah daya tarik wisata yang terkait dengan tradisi yang dipercaya masyarakat Dieng. Hingga saat ini di Dieng terdapat tradisi yang sejatinya bersumber tradisi Jawa-Hindu, yaitu tradisi pemotongan rambut anak gimbal ${ }^{7}$. Fenomena anak berambut gimbal ini berasal dari kepercayaan terhadap Kyai Kolodete. Masyarakat sekitar percaya jika rambut gimbal yang terjadi bukanlah kutukan melainkan titipan dari leluhur mereka, hanya saja rambut gimbal dianggap dapat menyebabkan terjadinya kendala, penyakit dan bahaya sehingga untuk menghilangkannya perlu diruwat $^{8}$ atau dilakukan upacara mencukur rambut gimbal.

Tradisi ruwatan merupakan satu budaya yang dilestarikan masyarakat Dieng. Tujuan tradisi ruwatan rambut gimbal agar segala bala yang ditimbulkan menjadi sirna. Anak yang memiliki rambut gimbal dianggap bisa membawa musibah atau masalah di kemudian hari, tapi bila diruwat maka anak tersebut dipercaya akan mendatangkan rejeki. Di samping itu ruwatan ini bertujuan agar si anak bisa hidup dengan rambut yang normal karena apabila rambut anak gimbal hanya dikeramas dan tidak diruwat maka akan tetap gimbal.

Ruwatan yang dilaksanakan masyarakat Dieng ini bahkan sejak tujuh tahun lalu

7 Gimbal berarti pial, gelambir atau bergumpal-gumpal. Pada anak yang mengalami fenomena berambut gimbal ini, rambutnya memang menjadi pial atau bergumpal-gumpal (Fajrin, 2009).

8 Ruwatan merupakan suatu ritual Jawa bertujuan untuk menghilangkan sukerta atau sengkala yang bermakna membuang segala pengaruh buruk pada diri manusia, karena dipercaya ada orang dengan kriteria tertentu yang membawa sukerta tersebut secara alami sejak lahir. Pada perkembanganya, ruwatan dilakukan untuk membersihkan pengaruh-pengaruh buruk pada suatu tempat atau orang-orang yang sedang mengalami kesulitan hidup, misalnya suatu daerah sering terkena bencana alam, wabah penyakit, atau seseorang sering mengalami musibah dan kesulitan ekonomi (Fajrin, 2009). 
telah dikemas sebagai event budaya dengan tajuk Dieng Culture Festival (DCF) ${ }^{9}$. Event DCF khususnya yang diselenggarakan di desa Dieng Kulon, Kabupaten Banjarnegara puncaknya ditandai dengan upacara pencukuran anak-anak berambut gimbal. Supeno (2016) menegaskan bahwa semula ritual pencukuran anak berambut gimbal dilakukan sendiri oleh orang tua mereka yang sering kali memberatkan karena biaya cukup mahal. Namun, ketika upacara itu dilaksanakan secara kolektif yang digagas Kelompok Sadar Wisata Dieng Pandawa Dieng Kulon justru mampu membantu keluarga yang kurang mampu bahkan event ini mampu menyedot perhatian wisatawan. Event ini sudah secara regular berlangsung di setiap bulan Agustus dan menjadi agenda wisata budaya (Fajrin, 2009; Kusumastuti, R.D. dan A. Prilantini, 2017).

\section{Keterlibatan Kelompok Sadar Wisata (Pokdarwis) Dieng Pandawa}

Satu bentuk kelembagaan pariwisata di tingkat lokal adalah Kelompok Sadar Wisata, biasa disingkat menjadi Pokdarwis. Fungsi utama dari Pokdarwis adalah menjadi mitra pemerintah, c.q. Dinas Pariwisata guna mendorong implementasi sadar wisata dan sapta pesona di masyarakat. Lembaga ini secara regulasi diatur oleh pemerintah dan secara struktural di bawah Dinas Pariwisata Provinsi dan kabupaten berkewajiban untuk melakukan pendampingan dan fasilitasi bagi Kelompok Sadar Wisata.

Dieng Pandawa sebagai salah satu entitas yang terdapat di desa Dieng Kulon adalah Kelompok Sadar Wisata. Kelompok ini dibentuk dengan maksud untuk menjadi semacam lembaga forum rembug/komunikasi masyarakat pariwisata Kawasan Dieng. Pokdarwis Dieng Pandawa berada di Desa Dieng Kulon. Pokdarwis ini menjadi contoh model pemberdayaan masyarakat yang mendorong lahirnya pokdarwis-pokdarwis lainnya di kawasan Dieng. Sebagai sebuah organisasi, pokdarwis ini memiliki visi terwujudnya pariwisata Dieng yang bermutu, berdaya saing, dan bermanfaat bagi kesejahteraan masyarakat Dieng pada khususnya dan bangsa Indonesia pada umumnya. Dari visi yang dicita-citakan, misi yang dijalani lembaga ini mengarah pada upaya untuk mengembangkan industri wisata demi terciptanya lapangan kerja dan kesejahteraan masyarakat, mengkampanyekan Sapta Pesona (Aman, Tertib, Sejuk, Indah, Ramah Tamah, Kenangan) kepada masyarakat Dieng, meningkatkan SDM masyarakat Dieng terutama hal kepariwisataan, memanfaatkan/menggali potensi SDA Dieng dalam mendukung pariwisata sehingga ke depan depan lebih baik.

Kegiatan pariwisata di Dieng Kulon diawali sejak tahun 2006 yang diprakarsai oleh ketua karang taruna. Satu tahun kemudian, diresmikan oleh Kepala Dinas Kebudayaan dan Pariwisata Kabupaten Banjarnegara per 27 November 2007, SK DinBud Kab Banjarnegara No. 556/36.a. Pokdarwis Dieng Pandawa memiliki tugas membina dan mengarahkan masyarakat menjadi tuan rumah yang baik. Tugas pokdarwis Dieng Pandawa adalah mengenalkan Sapta Pesona, bertindak sebagai fasilitator bagi usahausaha masyarakat, dan bersama Pemerintahan Desa membuat link kepada lembagalembaga (pendidikan, pemerintah/dinas, perusahaan melalui CSR). Pokdarwis Dieng Pandawa sebagai pengelola Desa wisata Dieng Kulon tentunya bekerja sama dengan Pokdarwis lain selaku pengelola desa wisata lain, UPT Dieng selaku pengelola obyek wisata dan lembaga lainya untuk mengemas pemasaran pariwisata Dieng.

9 http://travel.kompas.com/read/2015/08/02/084100627/Festival.Budaya.Dieng.Magnet. Pariwisata.Jateng, diakses, 12 Januari 2018. 
Dalam manajemen lembaga ini ditetapkan adanya Pokja (kelompok kerja), yang terdiri atas Pokja Souvenir, Pokja Industri/Makanan Khas, Pokja Homestay, Pokja Guide/ Pemandu, Pokja Kamtibpar, dan Pokja Seni Budaya. Menariknya, Pokdarwis Dieng Pandawa memiliki konsep klaster (berjejaring) dengan dengan wisata lainnya, seperti desa wisata Karangsari, desa wisata Karang Tengah, desa wisata Sembungan, dan desa wisata Kepakisan. Dapat disebutkan bila perkembangan wisata di Dieng Kulon sebagai desa wisata menjadi contoh bagi pengembangan desa wisata lainnya. Untuk wilayah Dieng, diibaratkan Dieng Kulon sebagai "orbitnya" yang keberadaannya juga saling memberikan maanfat kepada desa-desa lainnya sebagai "satelit"nya.

Sepak terjang lembaga Pokdarwis ini ternyata memiliki reputasi bagus. Pokdarwis Dieng Pandawa mendapatkan dua kali penghargaan di tingkat Jawa Tengah, pada tahun 2008 sebagai juara 3 lomba Apresiasi Sadar Wisata Jateng dan tahun 2009 sebagai juara 1 lomba yang sama. Pada tahun 2008 ketua Pokdarwis juga ditunjuk menjadi ketua klaster pariwisata Dieng dalam program Pengembangan Ekonomi Lokal Kabupaten Banjarnegara oleh FEDEP (Forum for Economic Development and Equiptmen promotion) Banjarnegara bidang Pariwisata, sehingga aktif dalam kegiatan pengembangan Klaster Jawa Tengah. Dieng Pandawa berhasil menjadi Juara I Homestay tingkat Provinsi Jawa Tengah (2010), ikut serta pameran pemberdayaan bersama Kementrian Kebudayaan dan Pariwisata 2011, dan berhasil mendapatkan penghargaan juara lomba kerajinan di tingkat daerah 2011 dan 2013, serta juara Desa wisata penerima PNPM Nasional tahun 2012.

\section{Rentetan Sejarab Bencana di Dieng}

Berdasarkan keputusan bersama Bupati Wonosobo dan Banjarnegara nomor 04/1995 dan 20/1995 tertanggal 20 Juli 1995, yang dimaksud dengan kawasan wisata Dieng mencakup tujuh desa. Lima desa berada di Kabupaten Banjarnegara, yaitu desa Bakal, desa Dieng Kulon, desa Karang Tengah, desa Pekasiran dan Kepakisan, sedang dua desa berada di wilayah Kabupaten Wonosobo, yaitu desa Dieng Wetan dan desa Sembungan. Adapun yang dimaksudkan dengan Dieng adalah kawasan yang meliputi desa Dieng Wetan (Kabupaten Wonosobo) dan Dieng Kulon (Kabupaten Banjarnegara) ${ }^{10}$.

Batas deliniasi wilayah Dataran Tinggi Dieng mencakup suatu area berupa dataran yang cukup luas di pegunungan Dieng yang dikelilingi oleh bukit dan gunung. Daerah tersebut secara geologis merupakan bekas danau purba berupa dataran yang luas. Saat ini meliputi desa Dieng (Wetan dan Kulon), Sikunang, Siterus, dan Njojogan (Sumedi, 2010, dalam Hermanto, 2015). Adapun yang dimaksud dengan Pegunungan Dieng adalah wilayah yang mencakup beberapa bagian dari kabupaten dengan Dataran Tinggi Dieng sebagai pusat wilayah dan dikelilingi oleh rumpun pegunungan Dieng yang memiliki keterkaitan, fisik, sosial, ekonomi dan budaya (Sumedi, 2010).

Dieng merupakan daerah rentan bencana ${ }^{11}$. Rentetan catatan sejarah bencana alam akibat gunung berapi dan tanah longsor masih dapat dijumpai ${ }^{12}$. Dari catatan sejarah bencana, pada tahun 1924, di kecamatan Kalibeber terjadi tanah longsor hebat

10 Untuk itulah dalam penelitian ini lebih difokuskan pada pengelolaan pariwisata di desa Dieng Wetan dan Dieng Kulon.

11 Lihat: www.academia.edu/9132782/Permasalahan_Bencana_di_Dieng, diakses 12 Januari 2018.

12 http://www.mediaindonesia.com/news/read/111115/di-balik-pesona-dieng-ada-bahaya-yang- 
sehingga hampir seluruh desa tertimbun. Tahun 1936 di dusun Timbang telah terjadi bencana gunung berapi, yaitu meletusnya Gunung Butak dan terjadinya kawah baru. Pada tanggal 4 Desember 1944 bencana terjadi lagi, kawah Sileri di desa Kepakisan mengeluarkan solfatara. Korban meninggal dunia 114 orang dan 38 orang luka-luka. Di tahun 1955, tepatnya tanggal 17 April, akibat adanya longsoran gunung yang terjadi di malam hari mengakibatkan desa Legetang tertimbun tanah ${ }^{13}$ dan sebanyak 332 orang meninggal dunia (Setyobroto,1959). Kembali, aktivitas Kawah Timbang mengeluarkan luncuran uap air dan gas yang semakin jauh dari biasanya dan sangat membahayakan ${ }^{14}$.

Tabel 3. Aktivitas Vulkanik Erupsi Gunung Dieng

\begin{tabular}{|c|c|c|c|}
\hline No & Tahun & Nama Kawah & Keterangan \\
\hline 1 & 1786 & Kw. Dringo & jumlah korban tidak diketahui \\
\hline 2 & $1825 / 1826$ & Kw. Pakuwojo & \\
\hline 3 & 1847 & Kw. (?) & hujan abu \\
\hline 4 & 1928 & Kw. Timbang & 39 korban jiwa \\
\hline 5 & 1939 & Kw. Timbang & 10 korban jiwa \\
\hline 6 & 1944 & Kw. Sileri & 144 korban jiwa \\
\hline 7 & 1964 & Kw Sileri & Erupsi lumpur \\
\hline 8 & 1979 & Kw. Sinila & Erupsi freatik dan gas beracun, 149 korban jiwa \\
\hline 9 & 1984 & Kw. Sileri & Semburan lumpur \\
\hline 10 & 1986 & Kw. Sileri & Semburan lumpur \\
\hline \multirow{2}{*}{11} & \multirow{2}{*}{$\begin{array}{c}1991 \& \\
1992\end{array}$} & \multicolumn{2}{|r|}{ Terjadi peningkatan gempa bumi } \\
\hline & & \multicolumn{2}{|r|}{ Muncul Semburan Lumpur } \\
\hline 12 & 1993 & Kw. Padang Sari & Semburan lumpur \\
\hline 14 & 2003 & Kw. Sileri & Erupsi freatik \\
\hline 15 & 2006 & Kw. Sileri & Erupsi freatik \\
\hline 16 & Jan 2009 & Kw. Sileri & Erupsi lumpur \\
\hline 17 & Mei 2011 & Kw. Timbang & Muncul aliran gas $\mathrm{CO} 2$ \\
\hline 18 & 1 April 2018 & Kw. Sileri & Semburan lumpur \\
\hline 19 & 8 April 2018 & Kw. Sileri & Semburan lumpur \\
\hline
\end{tabular}

Sumber: Diolah dari, Badan Vulkanologi dan Mitigasi Bencana Dieng, 2014 dan Media Massa, 2018.

Nur Hamid (tt) menjelaskan bahwa di Dataran Tinggi Dieng erupsi freatik cukup sering terjadi. Hal itu dapat dilihat dari banyaknya jumlah kawah yang terbentuk, yaitu \pm 70 buah di bagian timur dan tengah kompleks, serta \pm 30 buah di bagian barat sektor Batur. Dalam kurun waktu 200 tahun terakhir, ada sedikitnya 10 erupsi freatik yang terjadi. Letusan freatik inilah yang merupakan bentuk bahaya dari kompleks Gunung

mematikan/2017-07-02

13 https://www.kaskus.co.id/thread/56d540a992523307168b4576/dukuh-legetang-desa-yanghilang-dalam-semalam/, diakses 12 Januari 2018.

14 https://www.cnnindonesia.com/nasional/20170703172609-20-225489/esdm-sebut-kawahtimbang-lebih-berbahaya-dari-Sileri, diakses 12 Januari 2018. 


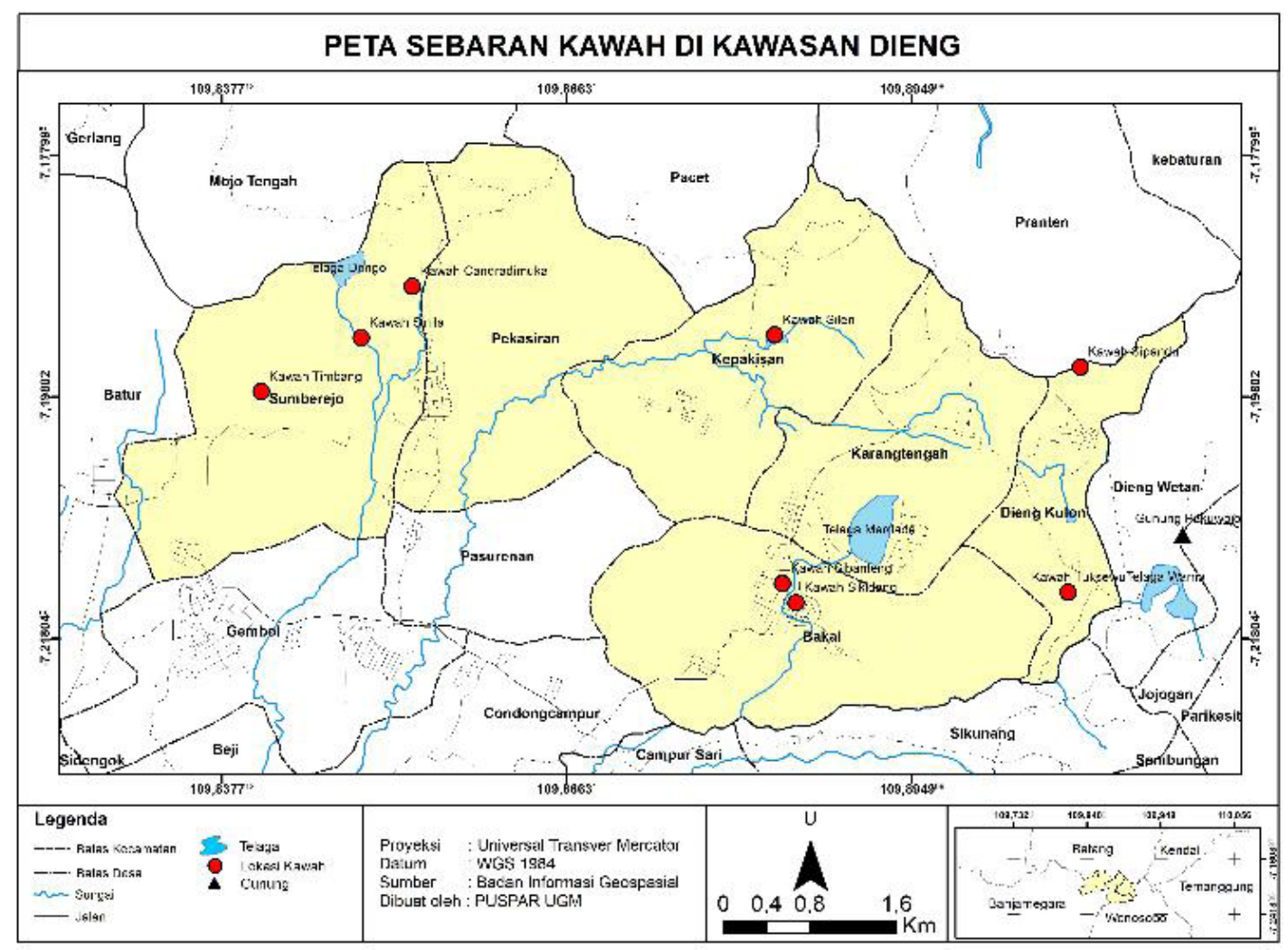

Gambar 5. Peta Sebaran Kawah di Kawasan Dieng

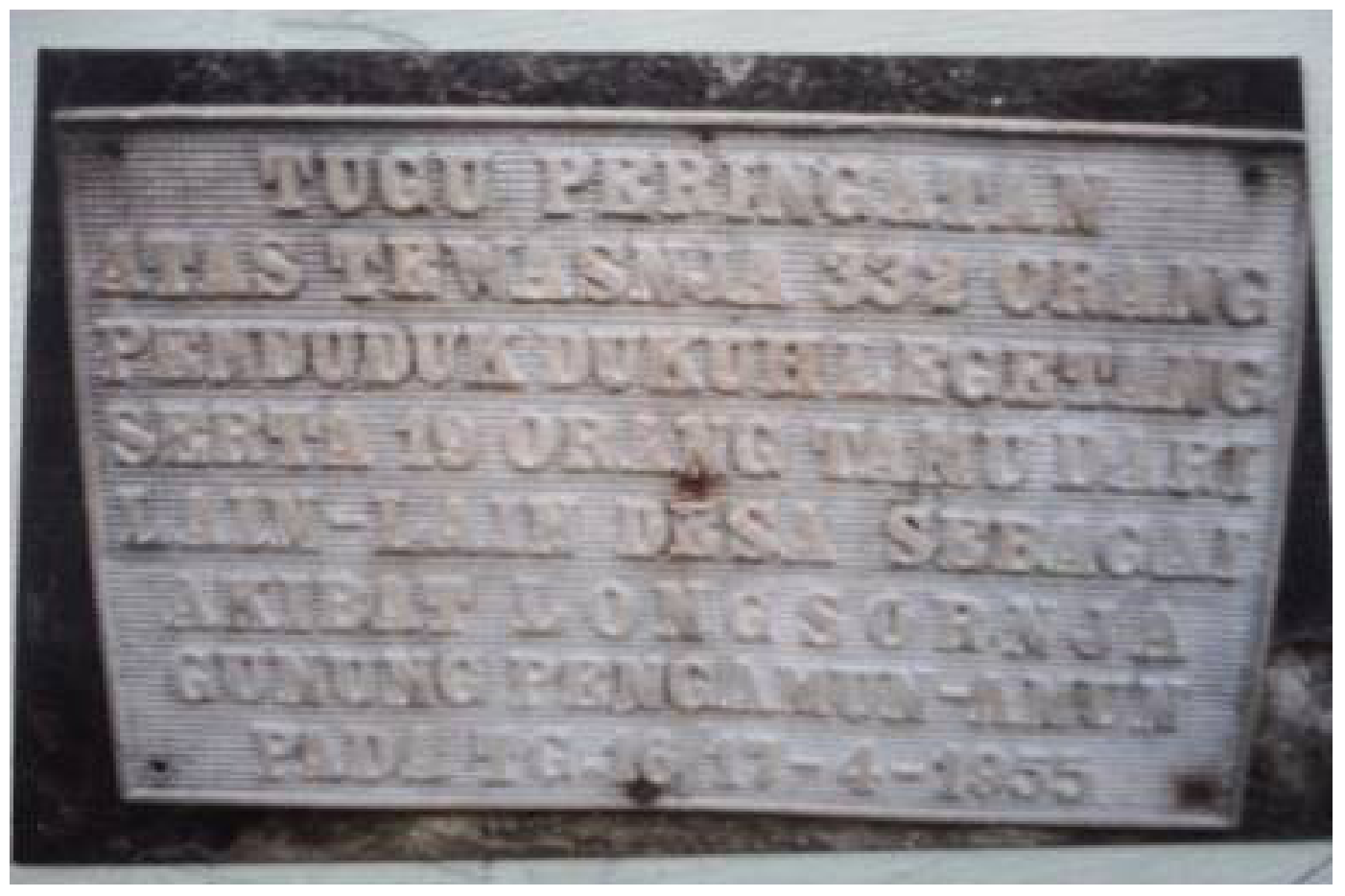

Gambar 6. Plakat yang terpasang di tugu peringatan dusun Legetang Sumber:https://www.kaskus.co.id/thread/56d540a992523307168b4576/dukuhlegetang-desa-yang-hilang-dalam-semalam/, diakses 12 Januari 2018 
Dieng (TKPKD, 2012). Menurut VSI erupsi freatik komplek Dieng dapat dibagi dalam dua katagori:

1. Erupsi tanpa adanya tanda-tanda (precursor) dari seismisity, yaitu hasil dari proses "self sealing" dari solfatara aktif (erupsi hydrothermal).

2. Erupsi yang diawali oleh gempabumi lokal atau regional, atau oleh adanya retakan dimana tidak adanya indikasi panasbumi di permukaan.

Erupsi dari tipe ini umum terjadi di daerah Graben Batur, sebagaimana diperlihatkan oleh erupsi freatik dari vulkanik Dieng pada Februari 1979. Kegiatan Gunungapi Dieng tidak memperlihatkan adanya letusan magmatik, setidaknya sejak tahun 1600 . Letusan lebih didominasi oleh aktivitas letusan freatik atau hydrothermal. Instansi yang berwenang (PVMBG) telah mengeluarkan area rawan dengan radius tertentu terhadap potensi semburan gas beracun dari kawah. Berlandaskan hasil pemetaan PVMBG, tim menyajikan peta jalur evakuasi dan titik kumpul (lihat peta di Gambar 7).

Selain potensi bahaya dari aktivitas kawah, dataran Tinggi Dieng termasuk wilayah yang sering mengalami longsor. Di awal tahun 2013, bencana longsor sempat terjadi di Desa Dieng Wetan Kecamatan Kejajar. Tebing setinggi tujuh meter longsor dan menimbun jalan utama Wonosobo-Dieng di kilometer 23. Kejadian ini sempat menyebabkan arus lalu lintas terhambat dan menyebabkan kemacetan jalur wisata tersebut. Longsor yang cukup parah juga pernah terjadi pada akhir tahun 2011. Longsor mengakibatkan satu orang meninggal, 10 orang hilang, enam orang luka berat, 13 rumah hancur, enam rumah rusak berat, dan enam rumah tanpa penghuni rusak berat.

\section{Refleksi Capaian Program}

\section{Penanggulangan Resiko Bencana Bencana di Dieng Kulon}

Penanggulangan bencana merupakan proses untuk mengurangi risiko yang diterima akibat bencana yang melanda di suatu daerah. Untuk mengurangi risiko tersebut dibutuhkan peran aktif seluruh pihak, baik masyarakat maupun pemerintah. Dalam rangka meningkatkan ketangguhan dan mengefektifkan proses penanggulangan bencana maka pemerintah pada tingkat terendah (pemerintah desa) harus mempunyai kemampuan dalam mengorganisir pengelolaan bencana yang ada di wilayahnya.

Desa Wisata Dieng Kulon merupakan salah satu destinasi wisata andalan di Indonesia yang banyak menarik wisatawan baik lokal maupun manca Negara. Salah satu tujuan kedatangan wisatawan adalah untuk menikmati keunikan alam Desa Wisata Dieng Kulon dan sekitarnnya. Keunikan alam Dieng merupakan berkah bagi masyarakat, akan tetapi di balik keindahan alam Dieng banyak menyimpan berbagai potensi ancaman bahaya yang setiap waktu dapat berubah menjadi bencana. Berdasarkan data historis, Kawasan Dieng setidaknya mempunyai tiga potensi bencana alam yaitu bencana gempa bumi, bencana tanah longsor, dan bencana gas beracun. Potensi bencana tersebut telah terbukti mempunyai dampak yang merugikan masyarakat di antaranya kerugian materiil, terganggunya aktivitas sehari-hari masyarakat bahkan hingga kerugian nyawa.

Kegiatan pengurangan risiko bencana di daerah Wisata Desa Dieng Kulon memerlukan sebuah perencanaan yang terstruktur agar setiap unsur pelaksana memahami tugas dan tanggung jawabnya. Dokumen standar operasional prosedur memuat langkah- 
langkah apa saja yang dapat dilakukan masyarakat dan pemerintah untuk mengurangi risiko bencana pada saat pra-bencana, saat bencana, dan pasca bencana. Selain itu, dokumen juga memuat alur koordinasi antar pelaksana agar tidak terjadi tumpang susun pengambilan keputusan.

Tabel 4. Koordinasi antar Pelaksana Penangulangan Bencana

\begin{tabular}{|c|c|c|}
\hline Unsur pelaksana & Jenis tindakan & Hasil tindakan \\
\hline \multirow{4}{*}{ Kepala desa } & $\begin{array}{l}\text { Berlaku sebagai ketua } \\
\text { tim tanggap darurat }\end{array}$ & $\begin{array}{l}\text { Bertanggung jawab pada seluruh } \\
\text { kegiatan tanggap darurat }\end{array}$ \\
\hline & Melaporkan kepada BPBD & Laporan \\
\hline & $\begin{array}{l}\text { Melaporkan kepada } \\
\text { pimpinan Kecamatan }\end{array}$ & Laporan \\
\hline & $\begin{array}{l}\text { Berkoordinasi dengan TAGANA, } \\
\text { POKDARWIS, dan PUSKESMAS. }\end{array}$ & \\
\hline \multirow{3}{*}{ TAGANA } & $\begin{array}{l}\text { Mengkondisikan masyarakat } \\
\text { menuju titik kumpul }\end{array}$ & $\begin{array}{l}\text { Masyarakat menuju titik } \\
\text { kumpul dengan tertib. }\end{array}$ \\
\hline & $\begin{array}{l}\text { Mempersiapkan tempat } \\
\text { pengungsian }\end{array}$ & $\begin{array}{l}\text { Tersedia barak pengungsian } \\
\text { dan logistik }\end{array}$ \\
\hline & $\begin{array}{c}\text { Melakukan penyelamatan } \\
\text { dan pencarian korban }\end{array}$ & \\
\hline POKDARWIS & $\begin{array}{l}\text { Menutup sementara akses } \\
\text { menuju Desa Dieng Kulon }\end{array}$ & $\begin{array}{c}\text { Tidak ada wisatawan masuk } \\
\text { pada saat keadaan darurat }\end{array}$ \\
\hline \multirow{4}{*}{ PUSKESMAS } & Mempersiapkan obat-obatan & \\
\hline & $\begin{array}{l}\text { Melakukan pertolongan } \\
\text { pertama pada korban }\end{array}$ & $\begin{array}{c}\text { Mencegah luka pada korban } \\
\text { bertambah parah }\end{array}$ \\
\hline & Melakukan assessment korban & $\begin{array}{c}\text { Laporan jumlah dan tingkat } \\
\text { kekritisan korban }\end{array}$ \\
\hline & $\begin{array}{l}\text { Melakukan assessment } \\
\text { kebutuhan medis korban }\end{array}$ & \\
\hline
\end{tabular}

\section{Kesepakatan Jalur Evakuasi dan Titik Kumpul di Dieng Kulon}

Hasil kegiatan hibah ESD yang dilaksanakan di Dieng Kulon ini juga mampu mengajak partisipasi perangkat desa, pengelola pariwisata dan tokoh masyarakat guna menyusun dan menyepakati jalur evakuasi dan lokasi titik kumpul sementara bila terjadi kejadian bencana. Berdasarkan pengalaman selama terjadinya kejadian bencana, justru desa Dieng Kulon ini menjadi tempat yang dipandang relatif aman. Dapat dikatakan apabila Dieng Kulon justru menjadi desa penampung bagi warga desa lainnya ketika desa mereka mengalami kejadian tertentu. Kepala desa Dieng Kulon beserta perangkat dan masyarakat setempat telah memiliki kesepakatan untuk jalur dan lokasi penampungan yang diperlukan untuk pengungsian. Beberapa lokasi titik kumpul antara lain terdapat di kantor balai desa Dieng Kulon, sekolah/madrasah, dan pos polisi Dieng Kulon, sekolah dasar Dieng Kulon. Hasil FGD dengan masyarakat dan pengurus serta perangkat juga menghasilkan kesepakatan untuk menetapkan alternatif titik kumpul lainnya, yaitu di lapangan Pandawa, di camping ground dekat terminal Aswatama, dan di halaman depan pendopo Soeharto Wietliem. 


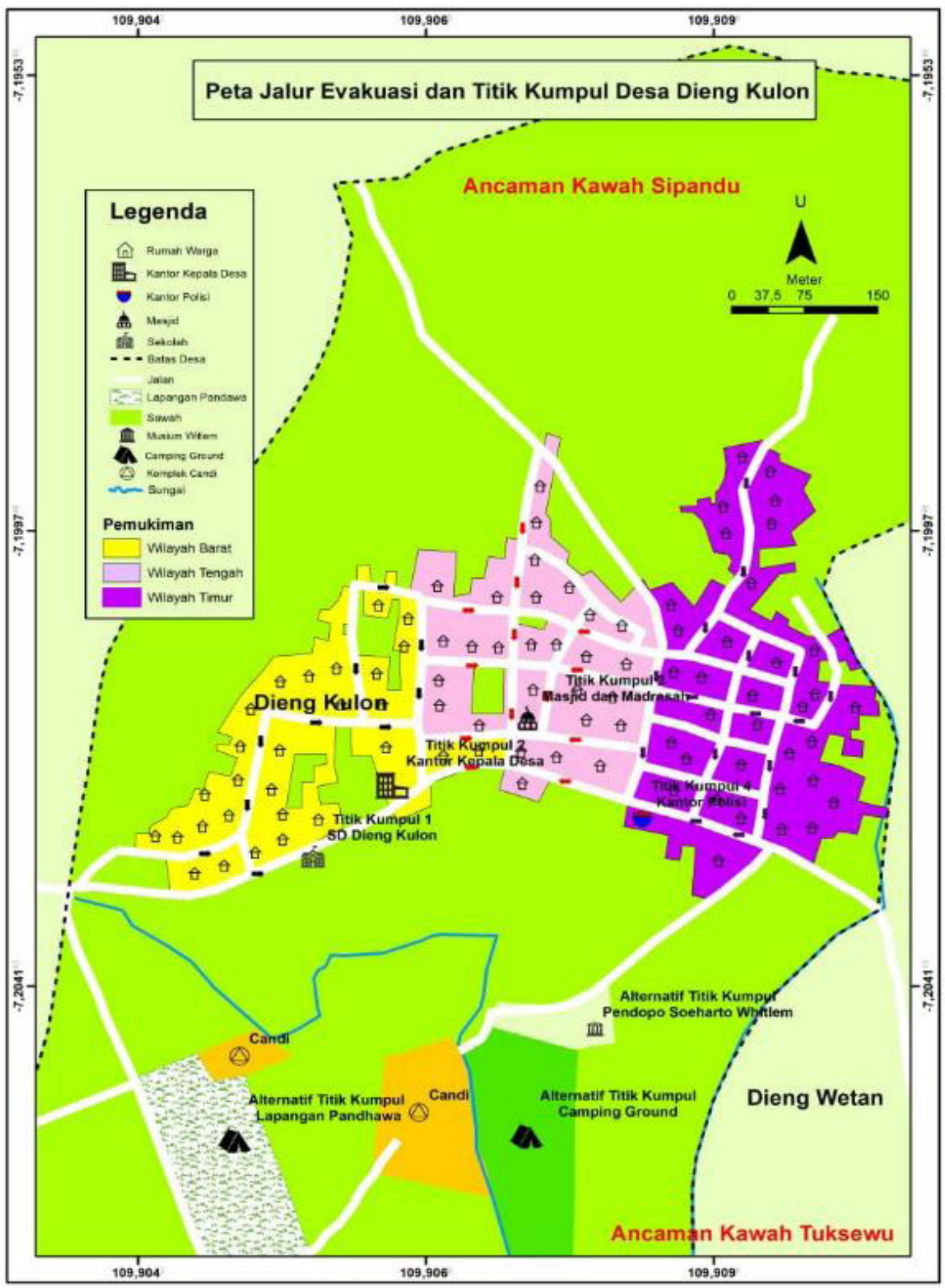

Gambar 7. Peta Jalur Evakuasi dan Titik Kumpul Desa Dieng Kulon 

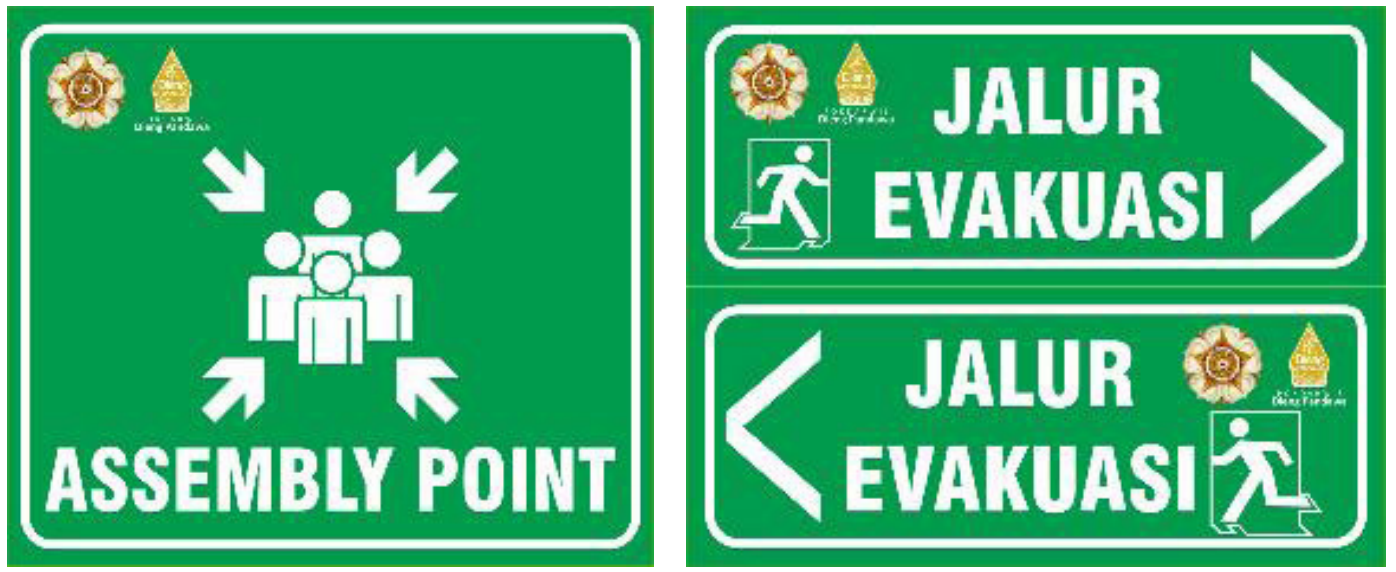

\section{Signage Jalur Evakuasi dan Titik Kumpul}

Pengelola pariwisata (Pokdarwis) Dieng Pandawa bersama tim ESD Puspar UGM pun dapat menyepakati diperlukannya signage atau tanda-tanda yang patut dipasang dan ditempatkan pada lokasi yang strategis. Tujuannya agar memudahkan warga dan wisatawan untuk menuju ke lokasi aman. Penanda jalur evakuasi direncanakan dipasang di beberapa perempatan gang di kampung Dieng Kulon yang dinilai memiliki kepadatan bangunan dan aktivitas masyarakat. Beberapa homestay di Dieng Kulon berada di dalam kampung bukan saja di pinggir jalan besar.

\section{Penutup}

\section{Kesimpulan}

Berikut ini dipaparkan beberapa kesimpulan yang berhasil diperoleh, yaitu:.

1. Ragam pesona dan daya tarik wisata di Dataran Tinggi Dieng perlu didukung dengan kesiapsiagaan Kelompok / Organisasi yang memiliki pengetahuan dan ketrampilan di bidang tanggap darurat.

2. Masyarakat desa Dieng Kulon, khususnya pengelola pariwisata yang tergabung dalam Kelompok Sadar Wisata (Pokdarwis) Dieng Pandawa perlu memiliki pemahaman tentang resiko ancaman bencana disebabkan Dieng Plateau merupakan destinasi pariwisata yang memiliki resiko bencana.

3. Dibutuhkan kesepahaman antar pihak guna mengutamakan keselamatan wisatawan khususnya dan bagi masyarakat di sekitar destinasi pariwisata, termasuk di Dieng Kulon agar destinasi wisata ini semakin mampu menerapkan salah satu prinsip dalam pembangunan wisata berkelanjutan.

\section{Saran}

Berikut ini dipaparkan beberapa saran yang dapat dijadikan pedoman dalam pengambilan kebijakan di objek wisata Dieng Kulon, yakni:

1. Diperlukan kerjasama antar pemangku kepentingan di destinasi pariwisata Dieng guna memberikan rasa ketenangan kepada wisatawan di kala mereka berwisata.

2. Diperlukan dukungan keamanan dan kenyamanan, termasuk perlunya kelengkapan 
informasi bagi wisatawan tentang kawasan/lokasi yang rentan bencana di Dieng Plateau, sehingga dapat diantisipasi bila terjadi hal yang tidak diharapkan.

\section{Daftar Pustaka}

Anonim, 2016. Profil Desa Dieng Kulon.

Antariksa, 2016. Kebijakan Pembangunan Kepariwisataan: Pengembangan Kepariwisataan yang Berkelanjutan dan Perlindungan Kekayaan Intelektual. Malang: Intrans Publishing.

Damanik, J. dan Frans Teguh. 2013. Manajemen Destinasi Pariwisata: Sebuah Pengantar Ringkas. Yogyakarta: Kepel Press.

Hamid, Nur. https://www.academia.edu/9132782/Permasalahan_Bencana_di_Dieng Hermanto, Heri. 2015. “Tunggal Bagenen-Botolan sebagai Kesadaran Transedental pada Pembentukan Permukiman di Pegunungan Dieng”, Disertasi. Fakultas Teknik, Universitas Gadjah Mada.

Holden, Andrew. 2008. Environment and Tourism. London: Routledge.

Kusumastuti, R.D. dan A. Prilantini, 2017. "Dieng Culture Festival: Media Komunikasi Budaya Mendongkrak Pariwisata Daerah”. Jurnal Studi Komunikasi, 1(2). doi: 10.25139/jsk.v1i2.182, diakses 12 Januari 2018.

Mubin, Nurul. 2016. Ritual Cukur Rambut Gimbal: Studi Makna Ritual bagi Pendidikan Moral Lingkungan dalam Komunitas Muslim Penghayat Kepercayaan Tunggul Sabdo Jati di Kawasan Dataran Tinggi Dieng. Yogyakarta: Pustaka Pelajar.

Ngabekti, Sri, Dewi Liesnoor Setyowati, R.Sugiyanto. 2007. “Tingkat Kerusakan Lingkungan di Dataran Tinggi Dieng sebagai Data Base Guna Upaya Konservasi”, Jurnal Manusia dan Lingkungan Vol.14 No. 2, Juli (2007): 93-102.

Nurlaila. 2014. "Tinjauan terhadap Konflik Kepentingan Pada Destinasi Wisata Dieng Plateau", Buletin Penelitian Destinasi Pariwisata", Vol. 1 (2014): 91-98.

Nurdiyansah. 2014. "Risk Disaster \& Crisis Management: Pariwisata di Antara Peluang dan Ancaman", dalam: Peluang dan Tantangan Pariwisata Indonesia. Bandung: Alfabeta. Hlm: 77-91.

Priatna. 2014. "Karakteristik gas vulkanik dan implikasinya terhadap daerah wisata di Dataran Tinggi Dieng", Jurnal Lingkungan dan Bencana Geologi, Vol. 5 No. 3 (2014): 159-172.

Sukatno, Otto. 2004. Dieng Poros Dunia: Menguak Jejak Peta Surga yang Hilang. Yogyakarta: IRCiSoD.

Supeno, Hadi. 2016. Inilah Dieng: Pesona, Potensi dan Misteri. Banjarnegara: CV. Natural Digital Printing.

Thohir, Mudjahirin. 2005. Memahami Kebudayaan: Teori, Metodologi, dan Aplikasi. Yogyakarta: Pustaka Pelajar.

Wahab, Salah dan John J. Pigram. 1997. Tourism Development and Growth: The Challenge of Sustainability. London: Routledge. 